\title{
Context in semantic information retrieval
}

\author{
FRANK DaPOLITO, DOUGLAS BARKER, and JOSEPH WIANT \\ University of Dayton, Dayton, Ohio 45409
}

Retrieval processes in word recognition were studied by systematically varying context conditions during testing. Ss received a single presentation of 30 triplets of semantically related words followed by a recognition test, with one word from each triplet being tested either in its original context, with the context deleted, in a new context of related words which primed a different meaning, or in a context of new unrelated words. Recognition performance was highest when the context remained unchanged and lowest when the target item was embedded in a new and unrelated context. No difference was found between the unchanged context and the semantically related context condition when $d^{\prime}$ values were used as a measure of recognition performance.

The present experiment is concerned with the registration and retrieval of semantic (linguistic) information in memory. A number of investigations have suggested that words which have multiple meanings have corresponding multiple representations in memory (Katz \& Fodor, 1963: Brown \& McNeill, 1966; Quillian, 1968). If this view is assumed, the question arises as to how tne ditferent meanings are entered into storage and how retrieval processes during word recognition determine the appropriate representation. Normally the actual meaning of a word must be specified by the particular embedding context as well as by visual and phonological features. This suggests that one approach to some important aspects of semantic retrieval is through a study of the effects of various context shifts upon word recognition.

A number of recent experiments have reported that semantic and association context changes do influence word recognition (Light \& Carter-Sobell, 1970; Tulving \& Thomson, 1971). In the study by Light and Carter-Sobell, ambiguous nouns were embedded in sentences and preceded by adjective modifiers which biased one semantic interpretation. Ss then received recognition tests on the nouns, which were presented without the adjective modifier, with the same modifier, or with an adjective which biased a different meaning. Recognition accuracy was greatly reduced when context adjectives biased a different semantic interpretation from that presented during study. These results were interpreted in terms of multiple representation theories of meaning.

The present study provides an extension of the results of Light and Carter-Sobell. The general method involved a single presentation of triplets of words for study (river-bank-shore), such that at least one word in each triplet had an alternative meaning which could be primed by altering the adjacent words in the triplet (money-bank-check). Thus, during the test phase, only one word in each triplet was probed for recognition, and $S$ was required to give a recognition response (yes/no) as well as a confidence rating. The principal goal was to compare recognition performance under conditions where the test context of the probed word was identical to that during training (river-bank-shore), removed (bank), replaced by semantically unrelated words (table-bank-coal), or replaced by new words which biased a different meaning (money-bank-check). In addition, the correct recognition of new words not previously experienced in the experiment was tested under the same context conditions. That is, new items (distractors) were presented in an old context related to the distractor, singularly, in a new context semantically unrelated words, or in a new context of semantically related words. These "corresponding distractors" were used to obtain an alternative estimate of recognition accuracy $\left(d^{\prime}\right)$, tas suggested by signal detection theory (Eqan, 1958).

$$
\text { SUBJECTS }
$$

The Ss were 48 undergraduate psychology students at the University of Dayton whose participation fulfilled a course requirement. The Ss were assigned randomly to two groups. MATERIALS

A two-channel tachistoscope (Scientific Prototype, Model 800-F) was used to present the stimuli. The learning material consisted of 30 white $5 \times 8$ in. cards, each card showing a triplet of three related words selected from Cramer (1970) with minor modifications for local dialect.

$$
\text { DESIGN }
$$

Each $\mathbf{S}$ served as his own control and was tested under four conditions. Each condition was composed of a standard test situation and its respective distractor, each having six cards with the target item asterisked on each of the 48 cards. Care was taken to insure that within each test condition the target item was counterbalanced with respect to serial position. Also, serial positioning was held constant on those particular words that were seen in both the training and the testing condition. No word was ever seen more than once during the testing period. Moreover, both the 30 training cards and the 48 testing cards were randomized for each S. Twenty-four Ss were given a training exposure time of $0.5 \mathrm{sec}$, and 24 Ss were given 1.0 sec. All were tested with an exposure time of $2.0 \mathrm{sec}$. The intertrial interval was held constant throughout training and testing at $10 \mathrm{sec}$ for all Ss.

The test conditions for old items and their respective distractors were: Condition 1 (old context) - a triplet seen during training vs a new word with two semantically related words from one of the training cards; Condition 2 (deleted context) - one word from a triplet seen during training vs one new word; Condition 3 (new, semantically related context)-an old word in a new and related context vs new triplet of related words; Condition 4 (new, unrelated context)-an old word in a new unrelated context vs a new word in a context of new unrelated words. Twenty-four of the training cards provided materials for testing the old items in Conditions 1-4, whereas six of the training cards provided the contexts for testing the new items in Condition 1.

\section{PROCEDURE}

After reporting to the testing room and being comfortably seated, Ss were read the following instructions: "You will be shown a deck of 30 cards with 3 common English words on each of the cards. Try to remember each of the 3 words on every card. Later on you will be tested to determine how many of the words you remember. Any questions?"

After being shown the 30 training cards, the following instructions were read aloud by $E$ : "Now you will be tested on the words you have just seen. On each card you will see some words, with an asterisk or star to the right of one of the words. For each starred word determine whether or not it is a word you have just studied. Answer 'yes' if it is and 'no' if you have never seen that word during the study period. Also indicate how certain you are of your response by saying 'one' if you are absolutely certain of your response, 'two' if you think you are correct but are not positive, or 'three' if your response was only a guess. Any questions?" 
Table 1

Correct Proportions of Old and New Test Items

Test Condition

\begin{tabular}{|c|c|c|c|c|}
\hline \multirow[b]{2}{*}{$\begin{array}{c}\text { Exposure } \\
\text { Time } \\
\text { (Sec) }\end{array}$} & 1 & 2 & 3 & 4 \\
\hline & $\begin{array}{c}\text { Old } \\
\text { Context }\end{array}$ & $\begin{array}{l}\text { Deleted } \\
\text { Context }\end{array}$ & $\begin{array}{c}\text { New } \\
\text { Related } \\
\text { Context }\end{array}$ & $\begin{array}{c}\text { New } \\
\text { Unrelated } \\
\text { Context }\end{array}$ \\
\hline & \multicolumn{4}{|c|}{ (Old/Y es) } \\
\hline $\begin{array}{l}0.5 \\
1.0\end{array}$ & $\begin{array}{l}.819 \\
.785\end{array}$ & $\begin{array}{l}.653 \\
.604\end{array}$ & $\begin{array}{l}.556 \\
.611\end{array}$ & $\begin{array}{l}.465 \\
.479\end{array}$ \\
\hline $\begin{array}{l}0.5 \\
1.0\end{array}$ & $\begin{array}{l}.694 \\
.771\end{array}$ & $\begin{array}{l}.688 \\
.799\end{array}$ & $\begin{array}{l}.847 \\
.875\end{array}$ & $\begin{array}{l}.903 \\
.917\end{array}$ \\
\hline
\end{tabular}

One $\mathrm{E}$ manned the materials, while another $\mathrm{E}$ recorded S's responses.

\section{RESULTS}

The proportions of old items recognized (hit rates) are summarized in the top portion of Table 1, while proportions of correct recognitions for new items (correct rejections) are presented in the lower half of the table. Entries are made for each combination of test context condition and exposure duration.

Visual inspection of the table shows that recognition of old items is best when tested under Condition 1 , with Condition 2 showing the next highest hit rates; Condition 4 shows the lowest hit rate performance. Thus, new unrelated words render hit rates to what appears to be chance level performance, while a new context which alters the meaning of the target item does not appear to disrupt recognition below that on the single-word test condition. It is clear that semantically unrelated new items disrupt recognition (hit rates) to a much greater degree than related contexts which prime different meanings of the target word.

An analysis of variance on the frequencies of correct old responses yielded a significant effect for test context, $F(3,132)=25.13(p<.01)$, but no statistical difference between exposure duration or its interactions. A Newman-Keuls analysis - indicated that the mean number of correct old responses was greater $(p<.05)$ under Condition 1 than under Conditions 2, 3 , and 4. While Conditions 2 and 3 were not significantly different, both yielded greater $(p<.05)$ mean numbers of correct old responses than did Condition 4.

In contrast to the results on old items, Table 1 shows that Conditions 1 and 2 do not differ in proportions of new items correctly rejected. Thus, testing in an old context does not reduce (or improve) correct rejections relative to the deleted context condition. However, the proportions of new items correctly rejected are very high for Conditions 3 and 4 .
Moreover, the large differences between old and new recognition proportions indicates a strong response bias which seems to be specific to Conditions 3 and 4 .

An analysis of variance on the frequency of correct new responses also yielded a significant context effect, $F(3,132)=14.56(p<.01)$, but no significant difference between exposure times and no interactions. A Newman-Keuls analysis indicated that while there was no difference between Conditions 3 and 4 , both were greater significant difference was found between Conditions 1 and 2 .

$A s$ an alternative measure of recognition performance, data were pooled over exposure durations, and memory operating characteristics (MOC) and 'd' vallues were calculated for each test condition, using the method recently developed by Gourevitch \& Galanter (1967) and Marascuilo (1970). The values for $\mathrm{d}^{\prime}$ for Conditions $1,2,3$, and 4 were $1.41,1.02,1.21$, and .92 , respectively. By this index of recognition accuracy, the best performance is again obtained in Condition 1 . However, Condition 3 shows the next highest performance, while Conditions 2 and 4 yield the values were evaluated by using the method developed by Marascuilo (1970). The results indicate that recognition in Condition 1 was significantly better than performance in Conditions 2 and 4 ( $p<.05$ in both cases). The only other comparison which reached significance was that between Conditions 3 and $4(p<.05)$. DISCUSSION

With respect to hit rates, these results are in agreement with those of Light \& Carter-Sobell (1970). Context alterations which presumably influence the semantic encoding of the test items produce large reductions in hit rates relative to Condition 1 , where the same context was present on both study and test phases. However, other context changes which cannot easily be viewed as altering the meaning or than Conditions 1 and $2(p<.05)$. No lowest. The differences between $d^{\prime}$ semantic encoding of the test item may produce equivalent or even greater reductions in hit rates. These results require that a general explanation, perhaps along the lines of Martin (1968), is needed in order to handle recognition failures produced by semantic, as well as nonmeaningful and nonlinguistic, context changes.

More importantly, the discrepancies between the conclusions obtained from hit rates and those suggested by the application of signal detection theory (SDT) immediately raise the question as to what extent the changes in hit rates across context conditions reflect changes in decision criteria rather than changes in recognition sensitivity. Light \& Carter-Sobell (1970) assert that in none of their three experiments was there a differential response bias. This is unlikely, since "some amount of response bias ... is almost always evident in forced-choice data [Green \& Swets, 1966, p. 409]." Moreover, the guessing correction technique employed by Light and Carter-Sobell has been shown to be unacceptable (Egan, 1958). "On the other hand, TSD provides a criterion-free measure of sensitivity or memory [Bernbach, 1971] ." For this reason, we prefer to draw conclusions from the $\mathrm{d}^{\prime}$ arialysis.

The fact that the $d^{\prime}$ values for Conditions 1 and 3 do not differ significantly indicates that semantic context changes which specify a memory representation different from that tagged during input do not necessarily damage recognition performance, although they may greatly affect Ss' decision processes. Also, this finding is not consistent with the results of Light and Carter-Sobell or the single meaning retrieval hypothesis suggested by them. Rather, our results suggest that during recognition tests, a specific semantic context permits $S$ to retrieve multiple semantic representations for a single word, especially if the representations are strongly coupled in an associative memory. Although all internal representations may not be searched, the multiple retrieval hypothesis seems more than a logical possibility, since associative responses to equivocal words depend upon comparisons of different meanings.

\section{REFERENCES}

BERNBACH, H. A. Recognition memory and signal detection analyses. Psychological Review, 1971, 78, 274.

BROWN, R., \& MCNEILL, D. The "tip of the tongue" phenomenon. Journal of Verbal Leaming \& Verbal Behavior, $1966,5,325-337$.

CRAMER、P. Magnitude and selectivity as independent factors in semantic generalization. Journal of Verbal 
Leaming \& Verbal Behavior, 1970, 9, 509-524.

EGAN, J. P. Recognition memory and the operating characteristic. Technical Note A FC R C - T N-58-51, Hearing and Communication Laboratory, Indiana University, Bloomington, Ind., 1958.

GOUREVITCH, V. \& GALANTER, E. A significance test for one parameter isosensitivity functions. Psychometrika, $1967,32,25-33$.

GREEN, D. M.. \& SWETS, J. A. Signal detection theory and psychophysics. New
York: Wiley, 1966.

KATZ, J. J., \& FODOR, J. A. The structure of semantic theory. Language, 1963, 39 , 170-210.

LIGHT, L. L., \& CARTER-SOBELL, L. Effects of changed semantic context on recognition memory. Journal of Verbal Learning Verbal Behavior, 1970, 9 , 1-11.

MARASCUILO, L. A. Extensions of the significance test for one-parameter signal detection hypotheses. Psychometrika, 1970, 35, 237-243.
MARTIN, E. Stimulus meaningfulness and paired-associate transfer: An encoding variability hypothesis. Psychological Review, 1968, 75, 421-441.

QUILLIAN, M. R. Semantic memory. In $M$. Minsky (Ed.), Semantic information processing. Cambridge: M.I.T. Press, 1968.

TULVING, E. \& THOMSON, D. M Retrieval processes in recognition memory: Effects of associative context. Journal of Experimental Psychology. $1971,87,116-124$.

\section{CURRENT LITERATURE ON HUMAN MEMORY}

DEY, M. K. (Jersey City State College, Jersey City, N.J. 07305). Reminiscence in paired-associate learning. British Journal of Psychology, 1971, 62, 41-51.

ELIAS, M. F. (Center for the Study of Aging and Human Development, Duke University Medical Center, Durh a m, N.C. 27706 ), BLENKARN, G. D., SIMMERMAN, S. J., \& MARSH, G. R. Administration of inhalation anesthetics to small animals: Some problems and solutions. Behavior Research Methods Instrumentation, 1971, 3, 70-71.

ELMES, D. G. (Washington and Lee University, Lexington, Va. 24450), \& ADAMS, C., III. Related responses in short-term memory. Journal of Experimental Psychology, 1971, 88, 140-141.

ERNEST, C. H. (University of Western Ontario, London, Canada), PAIVIO, A. Imagery and sex differences in incidental recall. British Journal of Psychology, 1971, 62, 67-72.

EYSENCK, H. J. (Institute of Psychiatry, University of London, London W.C.1, England), \& GRAY, J. E. Reminiscence and the shape of the learning curve as a function of subjects' ability level on the pursuit rotor. British Journal of
Psychology, 1971, 62, 199-215.

FORRESTER, W. E. (State University of New York, Oswego, N.Y. 13126), \& KING, D. J. Effects of semantic and acoustic relatedness on free recall and clustering. Journal of Experimental Psychology, 1971, 88, 16-19.

HABER, R. N. (University of Rochester, Rochester, N.Y. 14627). An alphanumeric display program for a PDP-8. Behavior Research Methods \& Instrumentation, 1971, 3, 141-145.

KELLAS, G. (University of Kansas, Lawrence, Kans. 66044), \& BUTTERFIELD, E. C. Effect of response requirement and type of material on acquisition and retention performance in short-term memory. Journal of Experimental Psychology, 1971, 88, 50-56.

McGLAUGHLIN, A. (University of Hull, Hull, England), \& DALE, $H$. C. A. Stimulus similarity and transfer in long-term paired-associate learning. British Journal of Psychology, 1971, 62, 37-40.

MCLEOD, P. D. (MCR Applied Psychology Unit, University of Cambridge, Cambridge, England), Williams, C. E., \& BROADBENT, D. E. Free recall with assistance from one and from two retrieval cues. British Journal of Psychology, $1971,62,59-65$.

PALMER, S. E., \& ORNSTEIN, P. A. (Princeton University, Princeton, N.J. 08540). Role of rehearsal strategy in serial probed recall. Journal of Experimental Psychology, 1971, 88, 60-66.

POLLIO, H. R. (University of Tennessee, Knoxville, Tenn. 37916), \& FOOTE, R. Memory as a reconstructive process. British Journal of Psychology, 1971, 62, 53-58.

RICH, R. (Monash University, Clayton, Victoria, Australia). Constant ratio rule for confusion matrices from short-term memory experiments. British Journal of Psychology, 1971, 62, 27-35.

SENF, G. M. (University of mlinois at Chicago, Chicago, Ill. 60680), \& ROLLINS, H. A. Effect of precuing versus postcuing retrieval order on the accuracy of bisensory memory. Journal of Experimental Psychology, 1971, 88, 12-15.

SHEEHAN, P. W. (University of New England, Armidale, N.S.W., Australia). The role of imagery in incidental learning. British Journal of Psychology, 1971, 62, 235-243. 